\author{
Marquette University \\ e-Publications@Marquette
}

\title{
Partially-Coupled d-q-0 Components of Magnetically-Isolated FSCW IPM Machines with Open-End-Winding Drives
}

\author{
Fan $\mathrm{Wu}$ \\ Marquette University \\ $\mathrm{Hao} \mathrm{Ge}$ \\ McMaster University \\ Ayman M. EL-Refaie \\ Marquette University, ayman.el-refaie@marquette.edu \\ Mohammad Farshadnia \\ University of New South Wales \\ Alireza Pouramin \\ University of New South Wales
}

See next page for additional authors

Follow this and additional works at: https://epublications.marquette.edu/electric_fac

Part of the Computer Engineering Commons, and the Electrical and Computer Engineering Commons

\section{Recommended Citation}

Wu, Fan; Ge, Hao; EL-Refaie, Ayman M.; Farshadnia, Mohammad; Pouramin, Alireza; and Dutta, Rukmi, "Partially-Coupled d-q-0 Components of Magnetically-Isolated FSCW IPM Machines with Open-EndWinding Drives" (2020). Electrical and Computer Engineering Faculty Research and Publications. 655. https://epublications.marquette.edu/electric_fac/655 


\section{Authors}

Fan Wu, Hao Ge, Ayman M. EL-Refaie, Mohammad Farshadnia, Alireza Pouramin, and Rukmi Dutta

This article is available at e-Publications@Marquette: https://epublications.marquette.edu/electric_fac/655 
Marquette University

e-Publications@Marquette

\section{Department of Electrical and Computer Engineering Faculty Research and Publications/College of Engineering}

This paper is NOT THE PUBLISHED VERSION.

Access the published version via the link in the citation below.

IEEE Transactions of Industry Applications, Vol. 56, No. 2 (2020, March-April): 1397-1407. DOI. This article is (C) Institute of Electrical and Electronic Engineers (IEEE) and permission has been granted for this version to appear in e-Publications@Marquette. Institute of Electrical and Electronic Engineers (IEEE) does not grant permission for this article to be further copied/distributed or hosted elsewhere without the express permission from Institute of Electrical and Electronic Engineers (IEEE).

\section{Partially-Coupled d-q-0 Components of Magnetically-Isolated FSCW IPM Machines with Open-End-Winding Drives}

\section{Fan $\mathrm{Wu}$}

Department of Electrical and Computer Engineering, Marquette University, Milwaukee, WI

Hao Ge

McMaster Automotive Resource Centre, McMaster University, Hamilton, Canada

Ayman M. El-Refaie

Department of Electrical and Computer Engineering, Marquette University, Milwaukee, WI Mohammad Farshadnia

School of Electrical and Telecommunication Engineering, University of New South Wales, Sydney, Australia

Alireza Pouramin 
School of Electrical and Telecommunication Engineering, University of New South Wales, Sydney, Australia

\section{Rukmi Dutta}

School of Electrical and Telecommunication Engineering, University of New South Wales, Sydney, Australia

\section{Abstract:}

Fractional-slot concentrated winding interior permanent magnet (FSCW-IPM) machines have been designed with very low winding mutual inductance for magnetic isolation features required for improving their fault-tolerant capabilities. These magnetically-isolated FSCW-IPM machines no longer adhere to the preconditions required for a conventional abc-to-dq0 transformation. As a result, it is found in this article that $d$-, q-axes could couple with 0 -axis in magnetically-isolated FSCW-IPM machines. Considering the second-order reluctance component, this phenomenon leads to thirdharmonic injection in phase voltages during normal operation, which can be cancelled out in terms of line-to-line voltage for $Y$-connected three-phase system. However, for open-end-winding machine drives without winding neutral point constraint, these voltage harmonics will show up in the winding voltage waveforms. Study shows that the amplitudes of these extra harmonics are determined by both saliency ratio and zero-axis current. The bandwidth of the proportional integral (PI) current regulator as well as switching frequency should be carefully determined to be able to take into account the major harmonics injected in phase voltages. Experimental verification on a 12-slot/10-pole prototype machine with spoke PMs has been carried out to show the impact of this phenomenon.

\section{SECTION I. Introduction}

Fractional-Slot concentrated winding (FSCW) permanent magnet (PM) synchronous machines have been receiving great interest for safety-critical applications attributable to their advantages in terms of magnetic, electric, thermal, and physical isolation features [1], [2]. Basically, for most of FSCW-PM machines having a slot per pole per phase (SPP) number of less than 1/2, especially for those with single-layer windings, the mutual inductance is negligibly small. Fig. 1(a) shows a three-phase 12-slot/10-pole all-teeth-wound FSCW interior permanent magnet (IPM) machine. By adopting the specific winding distribution, the flux generated by one phase tends to passes through the four teeth wound by four coils from the same phase rather than couple with other phases, as illustrated in Fig. 1(b). As a result, the mutual inductance for this type of machine is fairly small. Even with a high magnetic saturation design, the mutual inductance of a three-phase 12-slot/10-pole all-teethwound FSCW-surface permanent magnet (SPM) machine prototype is less than $3 \%$ of its self-inductance [3]. In [4], a study shows that the mutual inductance of a three-phase 12-slot/10-pole alternate- teeth-wound FSCWSPM machine prototype can be a few thousandths of its self-inductance (measured by an LCR meter). Moreover, there are persistent attempts to reduce the mutual inductance to even lower levels [5]. In this regard, simplified analyses generally assume that the mutual inductance between phases is zero. 


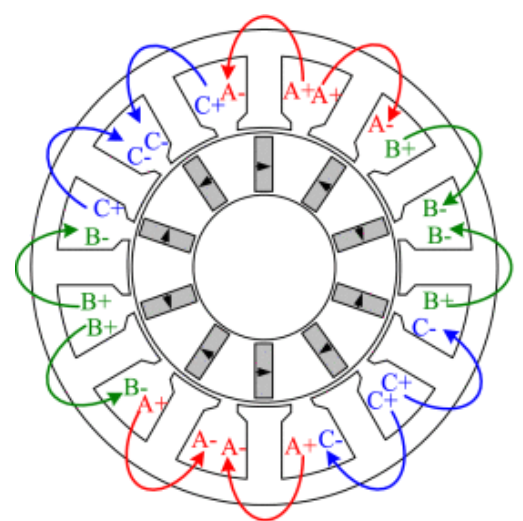

(a)

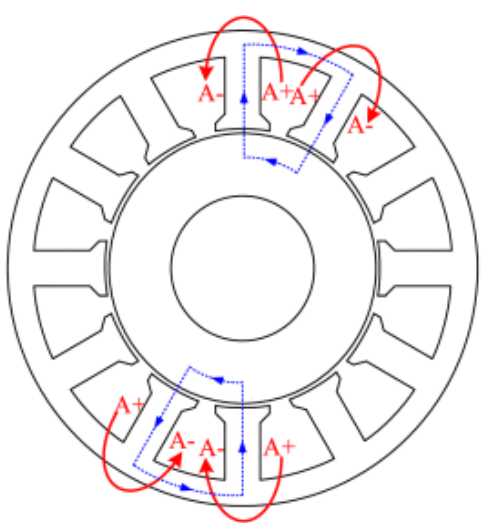

(b)

Fig. 1. 12-S/10-P all-teeth-wound FSCW-IPM machine. (a) Cross section. (b) Flux line produced by phase A winding.

Dynamic winding inductance as a function of machine rotor position and current excitation is of paramount significance for precise evaluation of machine performances like torque, losses, current ripple, etc. [6]. Through closed-form method or finite element (FE) simulation, the dynamic winding inductance can be predicted with acceptable accuracy [7]. The method proposed in [8] adopts a magnet-frozen-permeability approach for inductance calculation in a PM machine. Computationally-effective analytical methods, such as magnetic equivalent circuit model, sample function method, vector diagram, etc., are used in analysis of winding inductance [9]-[10][11][12]. In [13], Terzic et al. provide a comparison of experimental methods in terms of measuring flux linkage and inductance.

Combined with IPM rotor, FSCW machines become even more appealing due to their additional merits of fieldweakening capability and possibility of utilizing reluctance torque [14]-[15][16]. In addition, rotor PMs of SPM machines are rather vulnerable to demagnetization in case of winding short-circuit fault, compared to IPM machines and flux switching machines [17], [18]. Adopting an IPM design and reducing PM usage can have a significant impact on improving the reliability of the FSCW-PM machine drive system.

Conventional direct-quadrature-zero $(d-q-0)$ transformation from a coupled 3-phase reference frame (usually referred to as " $a-b-c$ " reference frame) to a decoupled $d-q-0$ reference frame is based on the assumption that the mutual inductances should be non-zero in a PM synchronous machine. In addition, the amplitude of the second-order components of winding self-inductance $\left(L_{S 2}\right)$ and mutual inductance $\left(M_{S 2}\right)$ should be identical $\left(L_{S 2}=M_{S 2}\right)$ [18]. These assumptions have been theoretically proven to be true for distributed-winding (DW) IPM machines. However, the magnetically-isolated FSCW IPM machines no longer adhere to these assumptions, which could lead to different results after applying conventional $d-q-0$ transformation.

The objective of this article is to investigate the influence of negligible winding mutual inductance on the fieldoriented control of FSCW-IPM machines, highlighting its impact in both pre- and postfault operations. For faulttolerant machine drives, the two key requirements are low mutual coupling between phases for fault isolation, and access to winding neutral point that can enable postfault operation. Thus, this article is focused on as follows.

1. FSCW-IPM machines with SPP lower than $1 / 2$ and with low mutual inductance between phase windings.

2. Machine drives without a neutral point constraint (open winding or semiopen winding).

This article is organized as follows. Section II theoretically describes the partially-coupled phenomenon in a magnetically- isolated FSCW-IPM machine. Section III provides detailed derivations showing its impact on open- 
end-winding machine drives. In Section IV, FE analyses of a three-phase all-teeth-wound 12-slot/10-pole FSCWIPM machine have been conducted as verification of the analytical and numerical results. Section $V$ covers experimental results and discussions on a prototype machine. Finally, conclusions are drawn in Section VI.

\section{SECTION II. Partially-Decoupled $d-q-0$ Transformation}

For a three-phase PM machine designed with a salient rotor, the flux linkage equation of phase $A$ winding is given as follows:

$$
\begin{aligned}
\psi_{A} & =L_{A A} I \sin \omega t+M_{A B} I \sin \left(\omega t-120^{\circ}\right) \\
& +M_{A C} I \sin \left(\omega t+120^{\circ}\right) \\
& =\left(L_{s 0}+L_{s 2} \sin 2 \theta\right) I \sin \omega t \\
& +\left(-M_{s 0}+M_{s 2} \sin 2\left(\theta+120^{\circ}\right)\right) \\
& \times I \sin \left(\omega t-120^{\circ}\right)+\left(-M_{s 0}\right. \\
& \left.+M_{s 2} \sin 2\left(\theta-120^{\circ}\right)\right) I \sin \times\left(\omega t+120^{\circ}\right)
\end{aligned}
$$

(1)

where $L_{A A}$ is self-inductance of phase $\mathrm{A}$ winding; $M_{A B}, M_{A C}$ denote mutual inductance between phases $\mathrm{A}$ and $\mathrm{B}$, phases $\mathrm{A}$ and $\mathrm{C}$, respectively; $L_{S 0}$ and $L_{S 2}$ denote the average (dc) component and the second order component of self-inductance of phase $\mathrm{A}$ winding, respectively; $M_{S 0}, M_{S 2}$ denote the average component and the secondorder component of mutual- inductance, respectively; $I$ is the amplitude of phase current; $\omega$ is angular frequency of phase current; and $\vartheta$ is the angle between $d$-axis and the axis of phase $A$ winding. Specifically, $\theta=$ $\omega t$.

In DW-IPM machine, it has been shown that the second order components of self- and mutual-inductance are equal

$$
M_{s 2}=L_{s 2}
$$

Assume that $i_{d}=0, \omega t=\theta$, then $\underline{(1)}$ turns into

$$
\begin{aligned}
\psi_{A} & =\left(L_{s 0}+M_{s 0}\right) I \sin \omega t+\frac{3}{2} L_{s 2} I \sin (2 \theta-\omega t) \\
& =\left(L_{s 0}+M_{s 0}+\frac{3}{2} L_{s 2}\right) I \sin \omega t
\end{aligned}
$$

(3)

which means that winding inductance is constant (independent of position angle $\theta$ ).

However, mutual inductance between different phases is negligibly small for an alternate-teeth-wound FSCWIPM machine. Therefore, assume that $M_{S 0}, M_{S 2}=0$, (1) can be written as

$$
\psi_{A}=\left(L_{s 0}+L_{s 2} \sin 2 \theta\right) I \sin \omega t
$$

in which winding inductance is variable rather than constant (dependent on position angle $\theta$ ). 
Fig. 2 shows a standard $a-b-c$ reference frame and rotating $d-q$ coordinate. Mathematically, the $d-q-0$ transformation can be regarded as diagonalization of stator winding inductance matrix. By applying the classical $d-q-0$ transformation matrix given as

$$
C=\left[\begin{array}{lll}
\cos \theta & -\sin \theta & 1 \\
\cos \left(\theta-120^{\circ}\right) & -\sin \left(\theta-120^{\circ}\right) & 1 \\
\cos \left(\theta+120^{\circ}\right) & -\sin \left(\theta+120^{\circ}\right) & 1
\end{array}\right]
$$

(5)

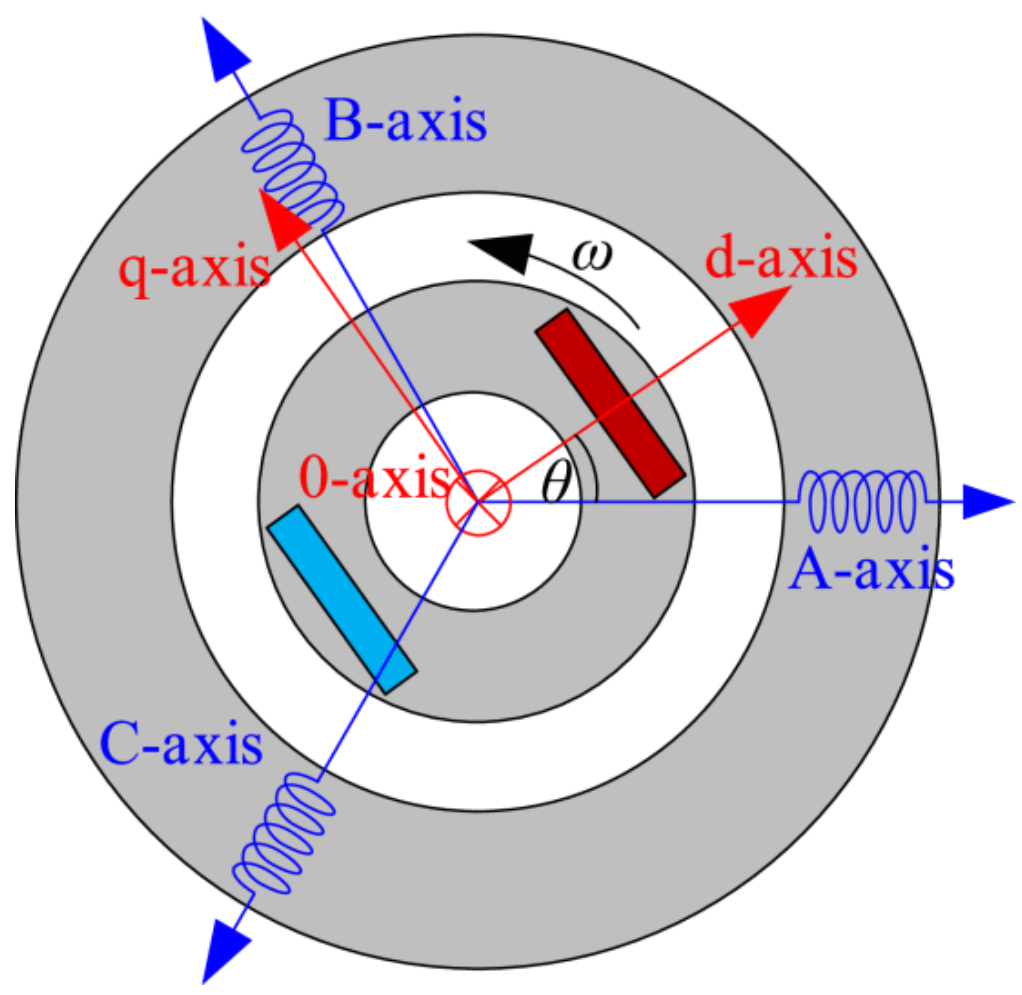

Fig. 2. Representatives of $d-q-0$ transformation in a three-phase IPM machine.

Winding inductance in $d-q-0$ reference frame is obtained

$$
L_{d q 0}=C^{-1} L_{s} C=\left[\begin{array}{lll}
L_{d} & 0 & -L_{\Delta} \sin 3 \theta \\
0 & L_{q} & L_{\Delta} \cos 3 \theta \\
-L_{\Delta} \sin 3 \theta & L_{\Delta} \cos 3 \theta & L_{0}
\end{array}\right]
$$

(6)

where $d$-axis inductance $L_{d}=L_{S 0}+0.5 L_{S 2} ; q$-axis inductance $L_{q}=L_{S 0}-0.5 L_{S 2} ;$ zero-axis inductance $L_{0}=$ $L_{S 0}$; coupled inductance $L_{\Delta}=0.5 L_{S 2}$; and stator inductance matrix in $a-b-c$ system is shown in unnumberd equation at the bottom of this page. 


$$
L_{s}=\left[\begin{array}{lll}
L_{s 0}+L_{s 2} \sin 2 \theta & 0 & 0 \\
0 & L_{s 0}+L_{s 2} \sin 2\left(\theta-120^{\circ}\right) & 0 \\
0 & 0 & L_{s 0}+L_{s 2} \sin 2\left(\theta+120^{\circ}\right)
\end{array}\right]
$$

As can be seen from (6), although $d$-axis and $q$-axis components remain decoupled (if cross coupling can be neglected), $d$-/ $q$ - axis and zero-axis are coupled. This phenomenon is referred to as "partially-coupled $d-q-0$ components" in this article. Since $d$-axis and $q$-axis are decoupled, conventional field-oriented control still works.

\section{SECTION III. Influences of Partially-Coupled d-q-0 Components on Machine}

\section{Drives Without Neutral Point Constraint}

Before further discussions, it should be clarified that: in order to keep a three-phase machine running in case of one-phase open-circuit, the sum of currents in the remaining two phases should not be zero. In other words, the invertor should be able to get access to the winding neutral point, such that the phase current can be flexibly manipulated. Basically, this is achieved by adopting cascaded full-bridge topology, three-phase four-leg topology or delta-connected winding topology [20], as shown in Fig. 3(b)-(d). It should be noted that, in any of these three topologies, the third voltage harmonic will not be automatically cancelled out.

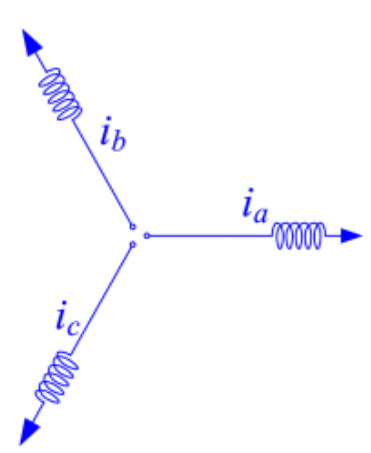

(a)

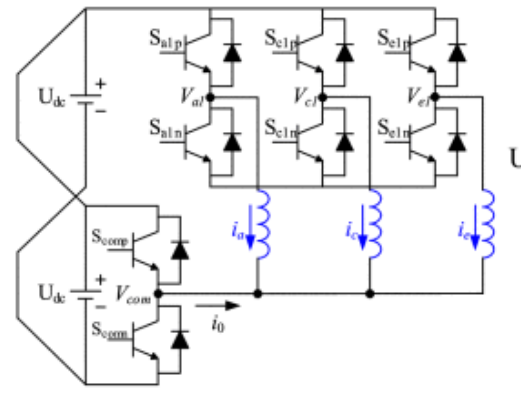

(c)

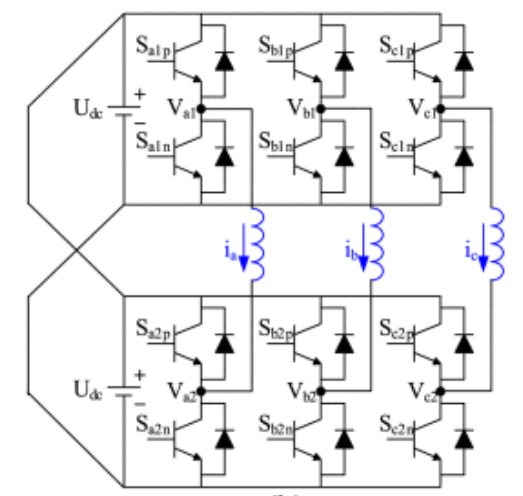

(b)

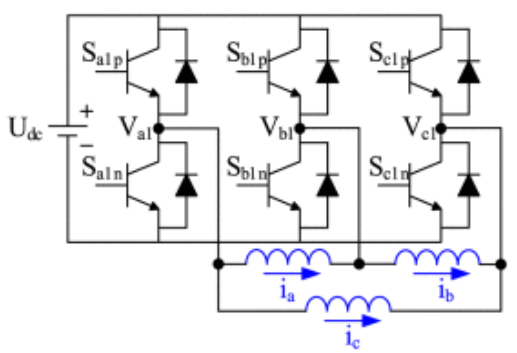

(d)

Fig. 3. 3-ph. VSIs and windings without neutral point constraint. (a) Open three-phase windings. (b) Cascaded full-bridge topology. (c) three-phase/four-leg topology. (d) Delta-winding.

For prefault operation, the sum of symmetrical three-phase currents yields to $i a+i b+i c=0$. Therefore, zero sequence current $\mathrm{i} 0=0$. Based on (6), flux linkage in $d-q-0$ reference frame is represented by 


$$
\psi_{d q 0}=\left[\begin{array}{c}
\psi_{d} \\
\psi_{q} \\
\psi_{0}
\end{array}\right]=\left[\begin{array}{c}
L_{d} i_{d}+\Psi_{p m} \\
L_{q} i_{q} \\
-\left(L_{\Delta} \sin 3 \theta\right) i_{d}+\left(L_{\Delta} \cos 3 \theta\right) i_{q}
\end{array}\right]
$$

(7)

where $i_{d}$ is $d$-axis current; $i_{q}$ is $q$-axis current; $\Psi_{p m}$ (with constant value) is flux linkage produced by rotor PMs. Then, voltage equation in $d-q-0$ reference frame can be calculated using Park's equation [19]

$$
\left\{\begin{aligned}
v_{d} & =\frac{d}{d t}\left(L_{d} i_{d}+\Psi_{p m}\right)-L_{q} i_{q} \omega-R_{S} i_{d} \\
& =L_{d} \frac{d i_{d}}{d t}+\frac{d \Psi_{p m}}{d t}-L_{q} i_{q} \omega-R_{S} i_{d} \\
v_{q} & =\frac{d}{d t}\left(L_{q} i_{q}\right)+\left(L_{d} i_{d}+\Psi_{p m}\right) \omega-R_{S} i_{q} \\
& =L_{q} \frac{d i_{q}}{d t}+\left(L_{d} i_{d}+\Psi_{p m}\right) \omega-R_{S} i_{q} \\
v_{0} & =\frac{d}{d t}\left(-L_{\Delta} \sin 3 \theta i_{d}+L_{\Delta} \cos 3 \theta i_{q}\right) \\
& =3 \omega L_{\Delta} \cos (3 \omega t) i_{d}-L_{\Delta} \sin (3 \omega t) \frac{d i_{d}}{d t} \\
& -3 \omega L_{\Delta} \sin (3 \omega t) i_{q}+L_{\Delta} \cos (3 \omega t) \frac{d i_{q}}{d t}
\end{aligned}\right.
$$

(8)

where RS is stator per-phase winding resistance. (8) can be further simplified as

$$
\left\{\begin{array}{c}
v_{d}=-L_{q} i_{q} \omega-R_{S} i_{d} \\
v_{q}=\left(L_{d} i_{d}+\Psi_{p m}\right) \omega-R_{S} i_{q} \\
v_{0}=3 \omega L_{\Delta}\left[\cos (3 \omega t) i_{d}-\sin (3 \omega t) i_{q}\right]
\end{array} .\right.
$$

(9)

By applying inverse transformation from $d-q-0$ reference frame to $a-b-c$ reference frame, the voltage expressions of phases A, B, and C are obtained as Eq. (10), shown at the bottom of the next page. 


$$
\begin{gathered}
{\left[\begin{array}{l}
v_{a} \\
v_{b} \\
v_{c}
\end{array}\right]=\mathrm{C}^{-1}\left[\begin{array}{l}
v_{d} \\
v_{q} \\
v_{0}
\end{array}\right]=\left[\begin{array}{ccc}
\cos \omega t & -\sin \omega t & 1 \\
\cos (\omega t-2 \pi / 3) & -\sin (\omega t-2 \pi / 3) & 1 \\
\cos (\omega t+2 \pi / 3) & -\sin (\omega t+2 \pi / 3) & 1
\end{array}\right]\left[\begin{array}{c}
-L_{q} i_{q} \omega_{r}-R_{S} i_{d} \\
\left(L_{d} i_{d}+\Psi_{p m}\right) \omega_{r}-R_{S} i_{q} \\
-3 L_{\Delta}\left[\sin (3 \omega t) i_{d}+\cos (3 \omega t) i_{q}\right]
\end{array}\right]} \\
=\left[\begin{array}{c}
\cos \omega t\left(-L_{q} i_{q} \omega_{r}-R_{S} i_{d}\right)-\sin \omega t\left[\left(L_{d} i_{d}+\Psi_{p m}\right) \omega_{r}-R_{S} i_{q}\right]-3 L_{\Delta} \sqrt{i_{d}^{2}+i_{q}^{2}} \sin \left(3 \omega t+\arctan \frac{i_{q}}{i_{d}}\right) \\
\cos (\omega t-2 \pi / 3)\left(-L_{q} i_{q} \omega_{r}-R_{S} i_{d}\right)-\sin (\omega t-2 \pi / 3)\left[\left(L_{d} i_{d}+\Psi_{p m}\right) \omega_{r}-R_{S} i_{q}\right] \\
-3 L_{\Delta} \sqrt{i_{d}^{2}+i_{q}^{2}} \sin \left(3 \omega t+\arctan \frac{i_{q}}{i_{d}}\right) \\
\cos (\omega t+2 \pi / 3)\left(-L_{q} i_{q} \omega_{r}-R_{S} i_{d}\right)-\sin (\omega t+2 \pi / 3)\left[\left(L_{d} i_{d}+\Psi_{p m}\right) \omega_{r}-R_{S} i_{q}\right] \\
-3 L_{\Delta} \sqrt{i_{d}^{2}+i_{q}^{2}} \sin \left(3 \omega t+\arctan \frac{i_{q}}{i_{d}}\right)
\end{array}\right]
\end{gathered}
$$


As can be seen in (10), the zero-axis voltage component will be injected into the A-, B-, and C-phase voltages as a third-harmonic component, of which the amplitude and phase angle are expressed as $3 L_{\Delta} \sqrt{i_{d}^{2}+i_{q}^{2}}$ and $\arctan \left(i_{d} / i_{q}\right)$, respectively. Since $L_{\Delta}=0.5 L_{S 2}$ ( $L_{S 2}$ is the second-order component of winding self-inductance, which reflects the rotor reluctance component), the amplitude of the injected third harmonic voltage is actually determined by rotor magnetic reluctance and stator current limit. In a Y-connected three-phase winding system, this third harmonic will be cancelled out in terms of line-to-line voltage. That is why these harmonics have not been accounted for in existing FSCW-IPM machine drives. However, in the cascaded full-bridge topology, threephase four-leg topology or delta-connected winding topology, these third harmonic components will show up in the line-to-line voltages.

\section{SECTION IV. Finite-Element Analysis}

A three-phase 12-slot/10-pole all-teeth-wound FSCW-IPM machine with spoke-type PMs is designed and studied through ANSYS Maxwell 2D. The machine has been optimized for a wide constant power speed range. Besides, a tradeoff study on characteristic current, efficiency, torque ripple, and material cost has been conducted in [21]. The key parameters of the designed machine are given in Table I while the machine cross section is shown in Fig. 4.

TABLE I Key Parameters of the FSCW IPM Machine

\begin{tabular}{|l|l|l|}
\hline Parameters & Units & Value \\
\hline outer diameter of stator & $\mathrm{mm}$ & 152 \\
\hline inner diameter of stator & $\mathrm{mm}$ & 90 \\
\hline airgap length & $\mathrm{mm}$ & 0.6 \\
\hline tooth width & $\mathrm{mm}$ & 14.62 \\
\hline magnet shape & $\mathrm{mm}$ & 4 (height), 17 (length) \\
\hline magnet remanence & $\mathrm{T}$ & $1.104\left(\mathrm{~N} 35 \mathrm{EH} @ 100^{\circ} \mathrm{C}\right)$ \\
\hline stator yoke thickness & $\mathrm{mm}$ & 7.0 \\
\hline slot opening & $\mathrm{mm}$ & 5.04 (width), 2.09 (height) \\
\hline bridge thickness & $\mathrm{mm}$ & 1.0 \\
\hline current density & $\mathrm{A}_{\mathrm{rms}} / \mathrm{mm}^{2}$ & 5.7 \\
\hline slot fill factor & $\%$ & 48 \\
\hline rated torque & $\mathrm{Nm}$ & $5.11 @ 1155 \mathrm{r} / \mathrm{min}$ \\
\hline
\end{tabular}

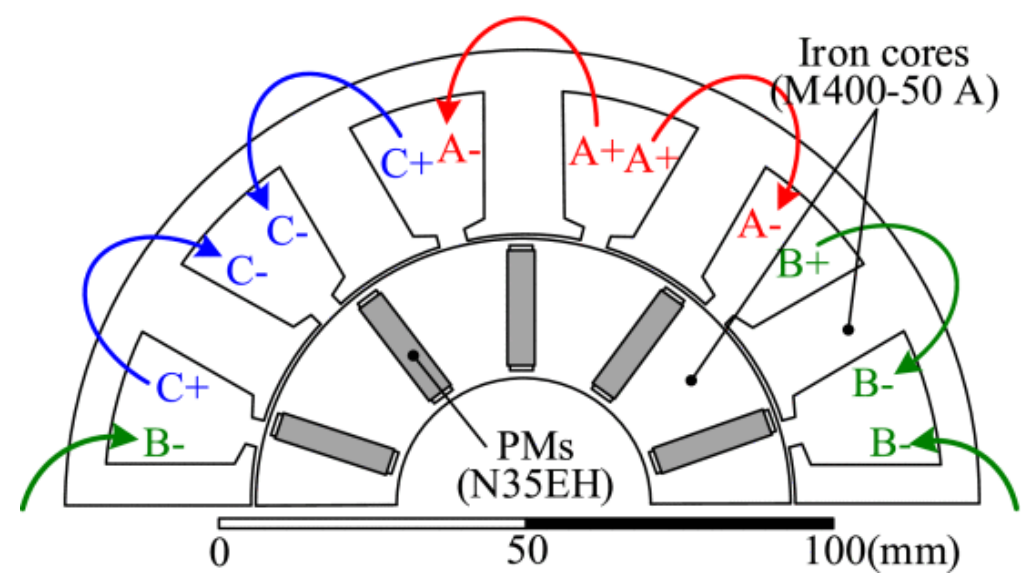

Fig. 4. Cross-section (1/2 module) of the three-phase 12-slot/10-pole FSCW-IPM machine with spoke PMs. 
The unsaturated (under no load condition) phase inductance waveforms within a single electric cycle are shown in Fig. 5. Key findings include the following.

1. Under no load condition, mutual inductances between phases are negligibly small (avg: $0.86 \mathrm{mH}$ ) compared to winding self-inductances [avg: $12.08 \mathrm{mH}$, refer to Fig. 5(a)]. In addition, both second and fourth-order harmonics can be observed in the spectrum of self inductances.

2. Mutual inductances between $d$-axis/q-axis and 0 -axis can be observed from Fig. 5(b), which feature significant third-harmonic components.

3. Under unsaturated condition, there are neither cross coupling between $d$-axis and $q$-axis nor harmonics shown in the waveform of $d$-/ $q$-/0-axis inductances.
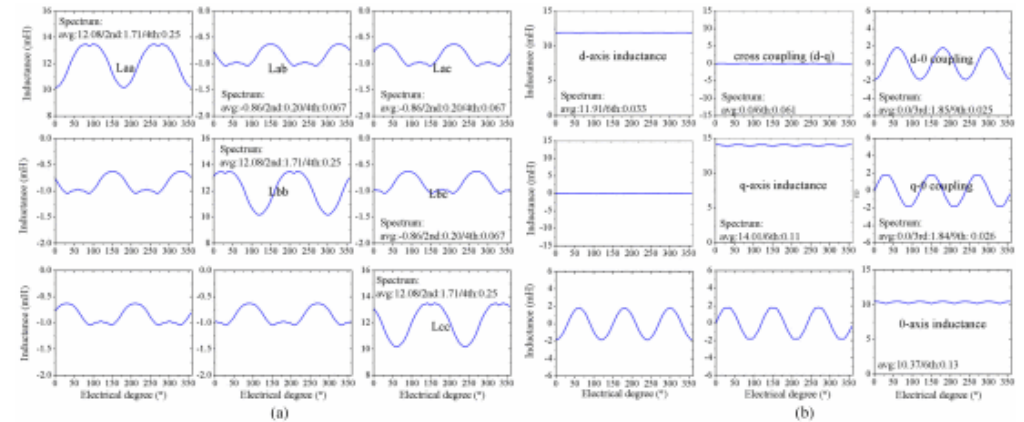

Fig. 5. Unsaturated inductance matrix of the 12-Slot/10-Pole FSCW-IPM machine in both $a b c$ and dq0 reference frames. (saliency ratio: 1.176). (a) Inductance matrix in $a b c$ reference frame. (b) Inductance matrix in dq0 reference frame.

Fig. 6 shows the inductance matrixes in full-load condition (speed: $1155 \mathrm{r} / \mathrm{min}$, torque: $5.11 \mathrm{~N} \cdot \mathrm{m}$ ). The inductances are calculated by inductance matrix computation function using incremental method in the ANSYS Maxwell 2D transient analysis. The dynamic curves of phase winding inductances are extracted for an electric cycle $(10.4 \mathrm{~ms}$ at $1155 \mathrm{r} / \mathrm{min})$ in order to analyze harmonic distribution. The winding inductances are shown in the $a-b-c$ reference frame first [see Fig. 6(a)] and then transformed into the $d-q-0$ reference frame [see Fig. 6(b)]. The average value and important harmonics are specified for each curve. Key findings are summarized as follows.

1. Compared with the unsaturated condition, the winding inductances consists of slightly higher even harmonic components while the mutual inductances go up a little bit.

2. As can be seen from Fig. 6(b), the even harmonics in phase windings result in the sixth harmonics in $d$ ,$q^{-}$, and 0 -axis inductances.

3. Cross coupling between $d$-axis and $q$-axis slightly goes up as well for load condition compared to no load condition. 

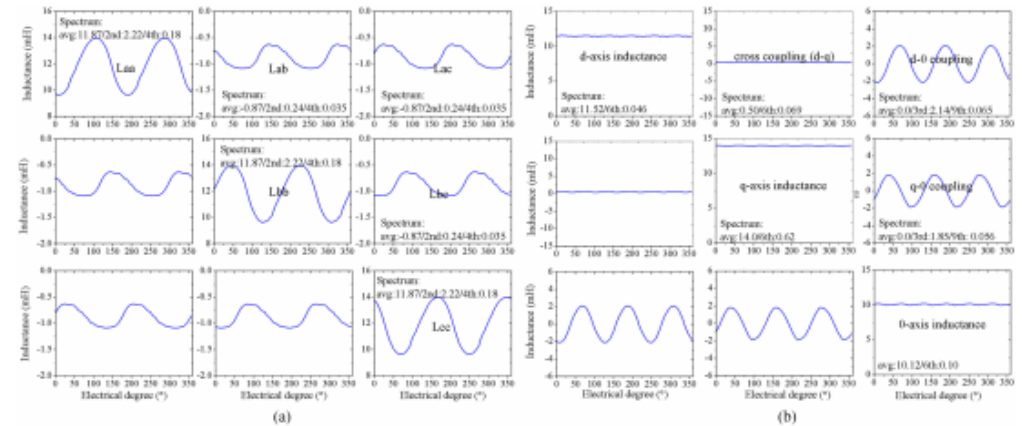

Fig. 6. Load inductance (Excitation: sinusoidal current $8.17 \mathrm{~A}, \gamma=17.8^{\circ}$, speed: $1155 \mathrm{r} / \mathrm{min}, T_{a v}=5.11 \mathrm{~N}$. $\mathrm{m}, \Delta T / T_{a v}=2.49 \%$, and saliency ratio: 1.215$)$. (a) Inductance matrix in abc reference frame. (b) Inductance matrix in dq0 reference frame.

Figs. 7 and 8 show the phase voltage waveform and spectrum with rated load, in which $i_{d}=--2.5 \mathrm{~A}$ and $i_{q}=$ 7.78A. In order to filter out the influence of PM-generated back electromotive force (EMF), the phase voltage due to the armature-reaction is obtained by subtracting the back EMF, as shown in Fig. 7. As can be seen in Fig. 8, the armature-reaction voltage contains significant third, fifth, ninth and other odd harmonic components. The second-order self-inductance component can only lead to third- and fifth-phase voltage harmonic. Other harmonic components are due to the fourth-order self-inductance components. By using similar approach to that illustrated in Section II, if the fourth-order self-inductance component is taken into account, (6) can be modified as

$$
\begin{aligned}
L_{d q} & =\left[\begin{array}{ccc}
L_{d} & 0 & L_{\Delta} \cos 3 \theta \\
0 & L_{q} & -L_{\Delta} \sin 3 \theta \\
L_{\Delta} \cos 3 \theta & -L_{\Delta} \sin 3 \theta & L_{0}
\end{array}\right] \\
+ & {\left[\begin{array}{ccc}
\frac{L_{S 4}}{2} \cos 6 \theta & -\frac{L_{S 4}}{2} \sin 6 \theta & \frac{L_{S 4}}{2} \cos 3 \theta \\
-\frac{L_{S 4}}{2} \sin 6 \theta & -\frac{L_{S 4}}{2} \cos 6 \theta & \frac{L_{S 4}}{2} \sin 3 \theta \\
\frac{L_{S 4}}{2} \cos 3 \theta & \frac{L_{S 4}}{2} \sin 3 \theta & 0
\end{array}\right] }
\end{aligned}
$$

(11)

where $L_{S 4}$ is fourth-order self-inductance component due to rotor saliency.

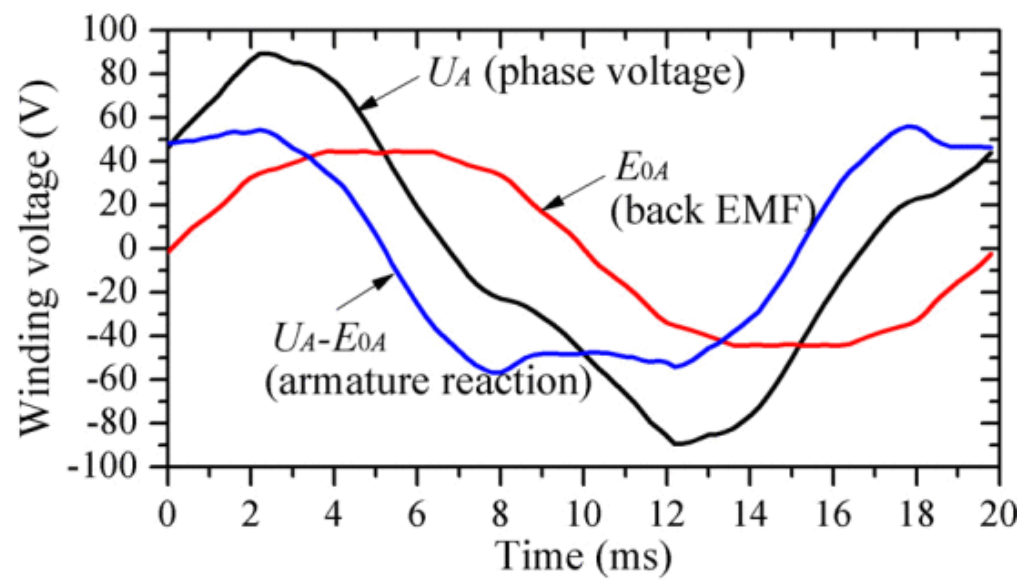


Fig. 7. Waveforms of phase $A$ voltages after subtracting the back EMFs (Excitation: sinusoidal current $8.17 \mathrm{~A}, \gamma=$ $17.8^{\circ}$ and speed: $\left.1155 \mathrm{r} / \mathrm{min}\right)$.

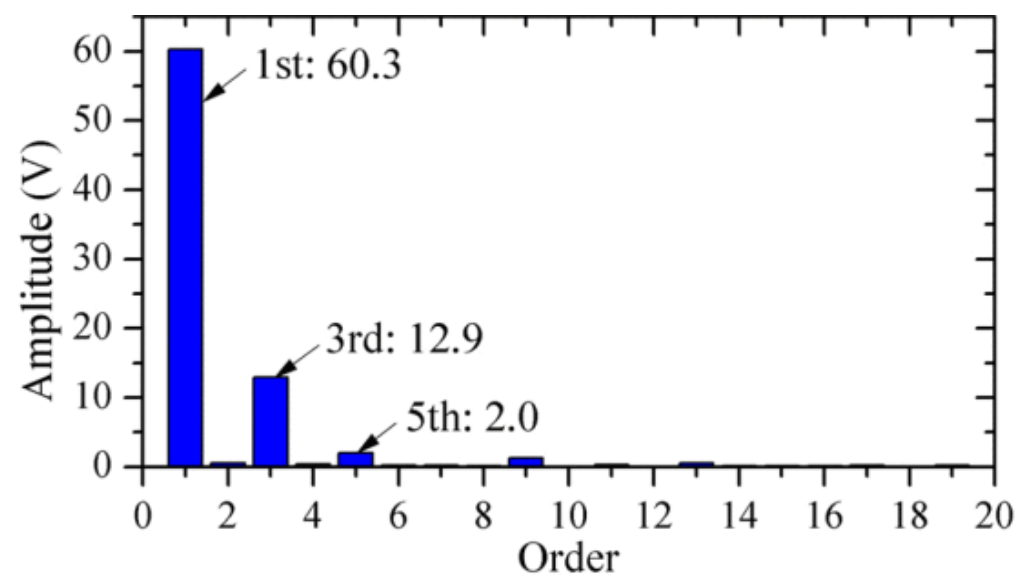

Fig. 8. Spectrum of phase $A$ voltages after subtracting the back EMFs (Excitation: sinusoidal current 8.17 A, $v=$ $17.8^{\circ}$, and speed: $\left.1155 \mathrm{r} / \mathrm{min}\right)$.

As can be seen in (11), the sixth-order harmonic components are introduced in $d$ - and $q$-axis self and mutual inductances. For the coupling terms between $d_{-}^{-}, q^{-}$, and 0 -axis, extra third-order harmonic components are also introduced. This effect is shown in Fig. 6(b) as well.

\section{SECTION V. Experimental Verification}

Figs. 9(a)-(c) demonstrates the stator assembly, rotor assembly of the protype machine, as well as the experimental setup. In order to reduce eddy current losses, the rotor magnets are segmented into three pieces as shown in Fig. 9(b). The prototype machine is coupled with a load motor (Kollmorgen motor) while the MATLAB/Simulink machine control model is downloaded to a dSpace DS1103 workstation for rapid control prototyping. The stator windings of the prototype machine are configured as $Y$-connected or open-end windings. A standard three-phase half-bridge inverter is used for the $Y$-connected- winding configuration while a fullbridge inverter comprises 12 switches is used to supply the open-end-winding configuration. 


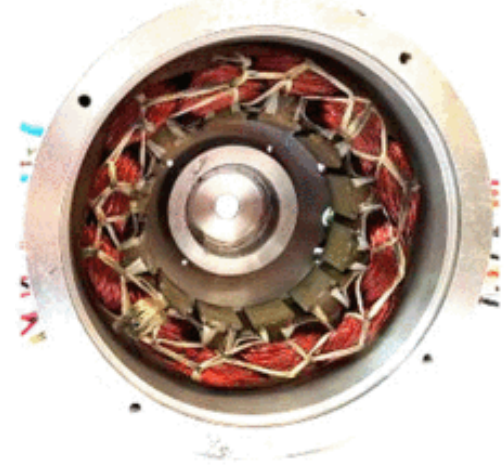

(a)

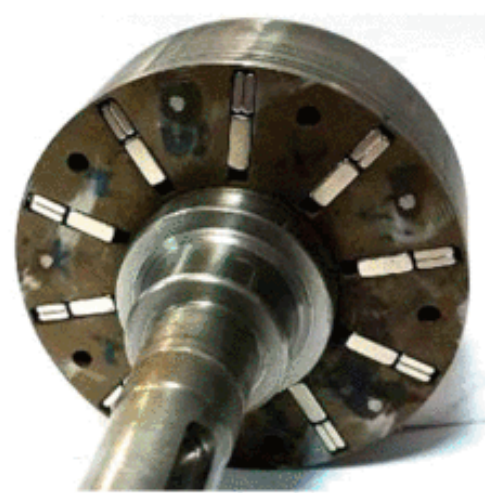

(b)

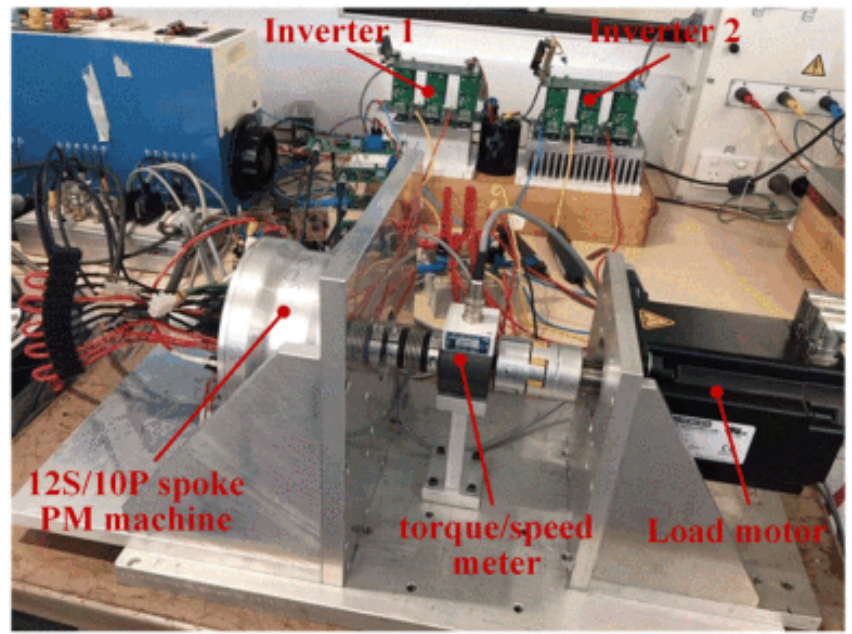

(c)

Fig. 9. Prototype machine and experimental setup. (a) Stator assembly. (b) Rotor assembly. (c) Experimental setup.

Fig. 10 shows the back EMF waveform at $600 \mathrm{r} / \mathrm{min}$. The testing results align well with the finite element analysis (FEA) results. Also, the third- harmonic component (amplitude: $1.45 \mathrm{~V}$ ) is only $5.7 \%$ of the fundamental component (amplitude: $25.16 \mathrm{~V}$ ). 


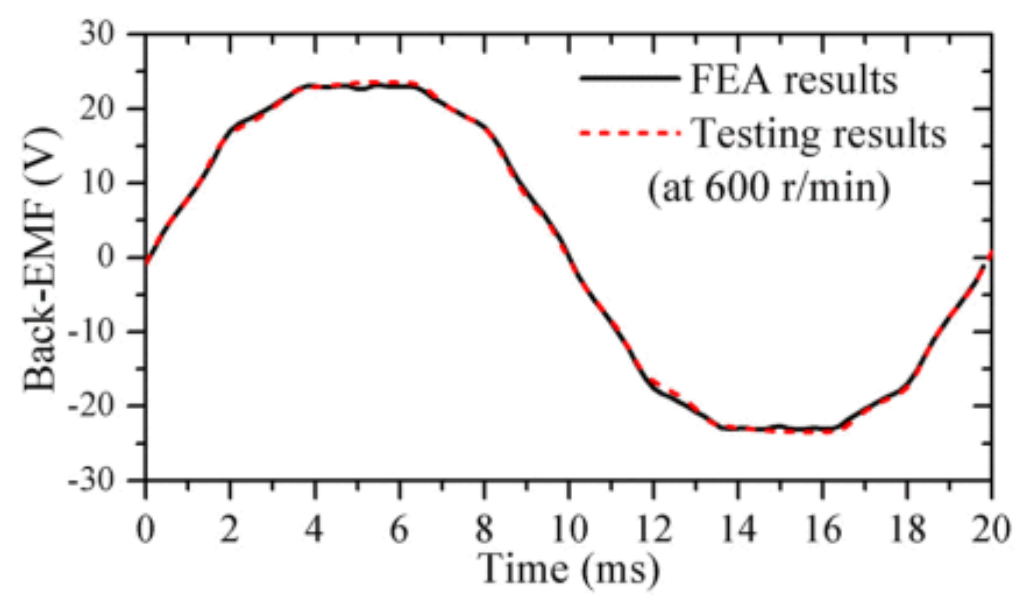

(a)

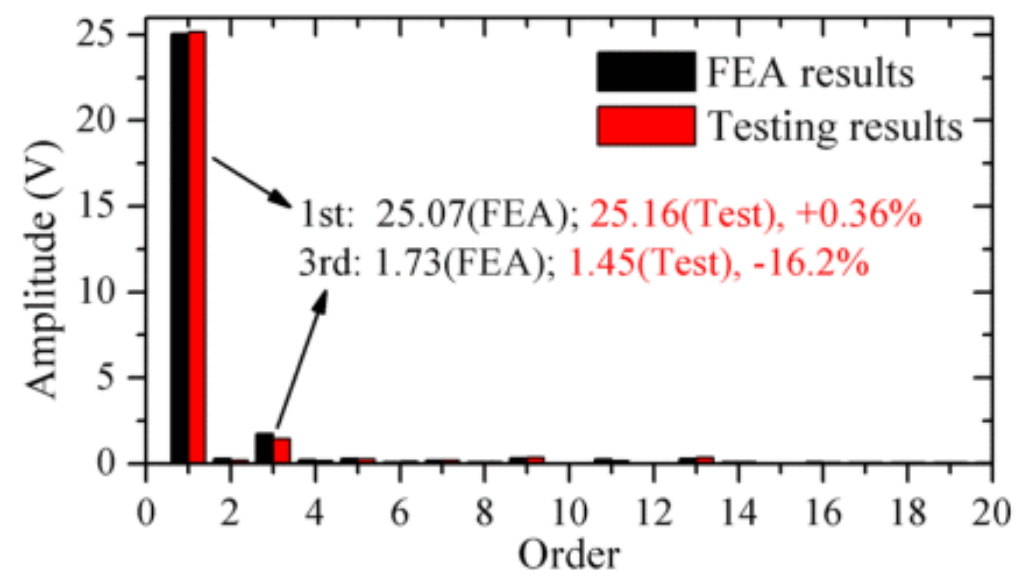

(b)

Fig. 10. Back EMF and spectrum. (a) Back EMF. (b) Spectrum of FEA and measured back EMFs.

Fig. 11 shows the winding current waveforms at $1155 \mathrm{r} / \mathrm{min}$ (corner speed), $1 \mathrm{hp}$ (maximum power). At the same operating point, the test is implemented using both Y-connected winding [see Figs. 11(a) and (b)] and open-end winding [see Figs. 11(c) and (d)]. The pulsewidth modulation (PWM) switching frequency is $10 \mathrm{kHz}$ for all tests while the dc-bus voltage is $150 \mathrm{Vdc}$. As can be seen from Fig. 11, winding current ripple of the open-end winding configura tion is higher than that of the Y-connected winding. However, these current ripples are mainly due to high-order harmonics. 


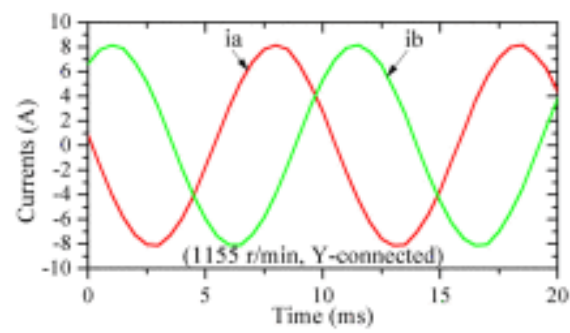

(a)

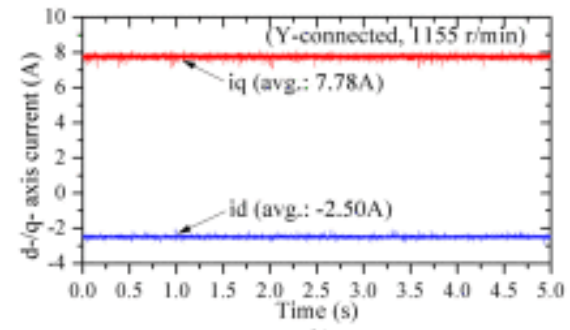

(b)

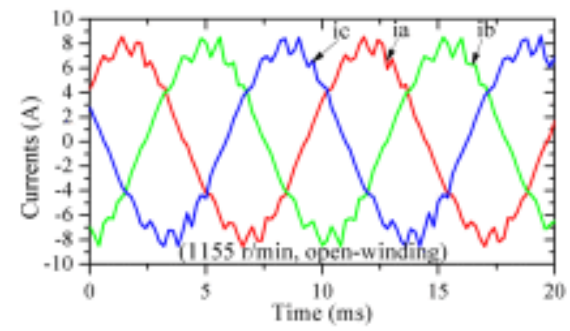

(c)

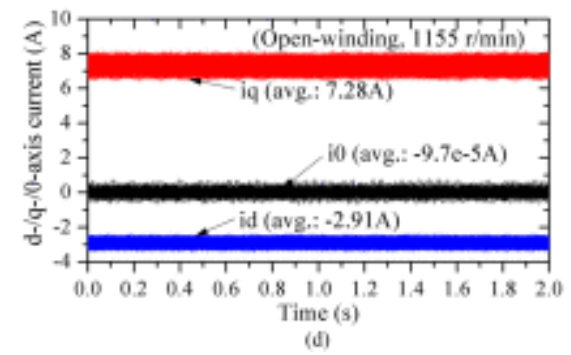

Fig. 11. Winding current waveforms at $1155 \mathrm{r} / \mathrm{min}$ with $\mathrm{Y}$-connected winding and open-end winding. (a) current waveform in phases $A$ and $B$ (Y-connected winding). (b) $d$-axis and $q$-axis current (Y-connected winding). (c) Current waveform in phases $\mathrm{A}$ and $\mathrm{B}$ (open-end winding). (d) $d$-axis, $q$-axis, and 0 -axis current (open-end winding).

Accordingly, winding voltage waveforms and spectrums using Y-connected winding and open winding are shown in Figs. 12 and 13, respectively. For the $Y$-connected winding configuration, the third-harmonic voltage accounts for $\sim 13.6 \%$ (1155 r/min, $5.1 \mathrm{~N} \cdot \mathrm{m}$, Fig. 12(b)] of the fundamental component. However, these third-harmonic components are cancelled out at line-to-line voltage. For open-end winding configuration, the third-harmonic voltage accounts for $\sim 17.8 \%$ (1155 r/min, $5.1 \mathrm{~N} \cdot \mathrm{m}$, Fig. 13(b)] of the fundamental component, which is higher than the results of the $\mathrm{Y}$-connected winding. 


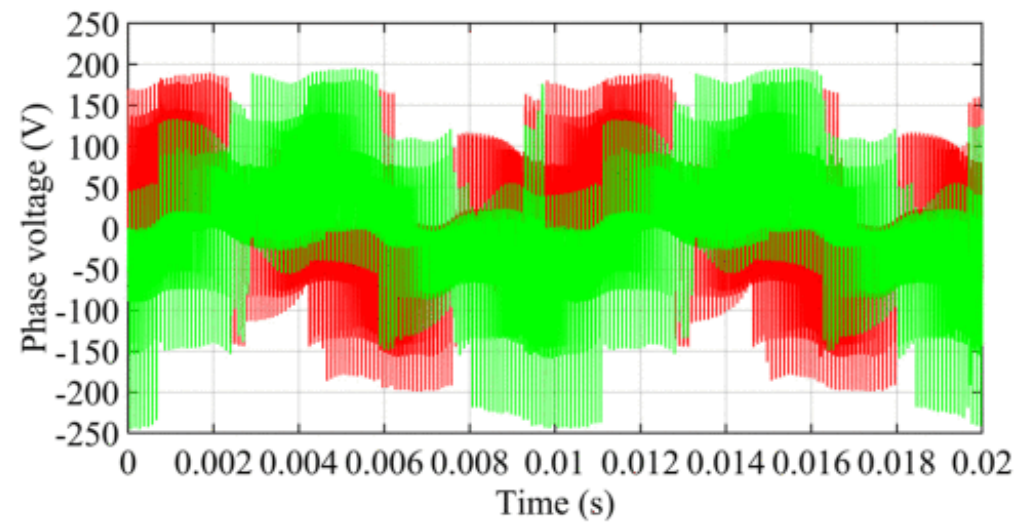

(a)

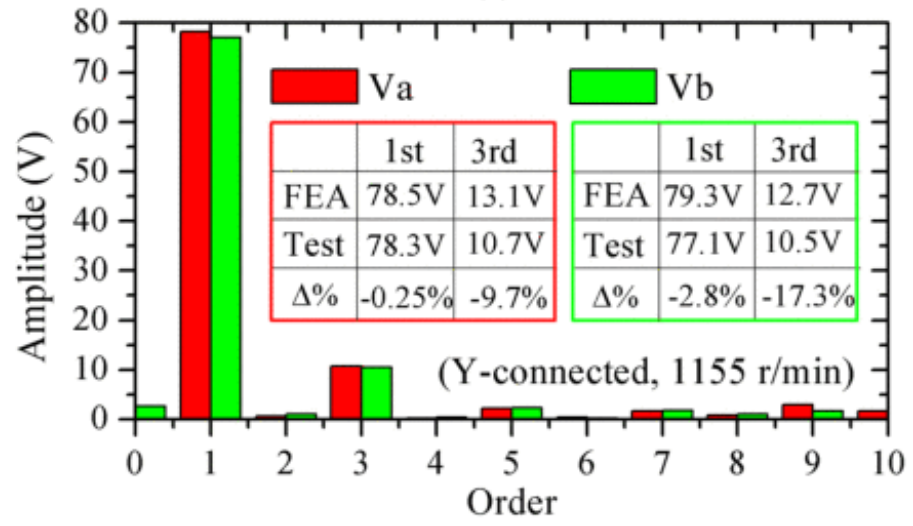

(b)

Fig. 12. Winding voltage waveforms at $1155 \mathrm{r} / \mathrm{min}$ with Y-connected winding. (a) Phase voltage waveform (red: $V_{a}$; and green: $V_{b}$ ). (b) Fast Fourier transform (FFT) of (a). 


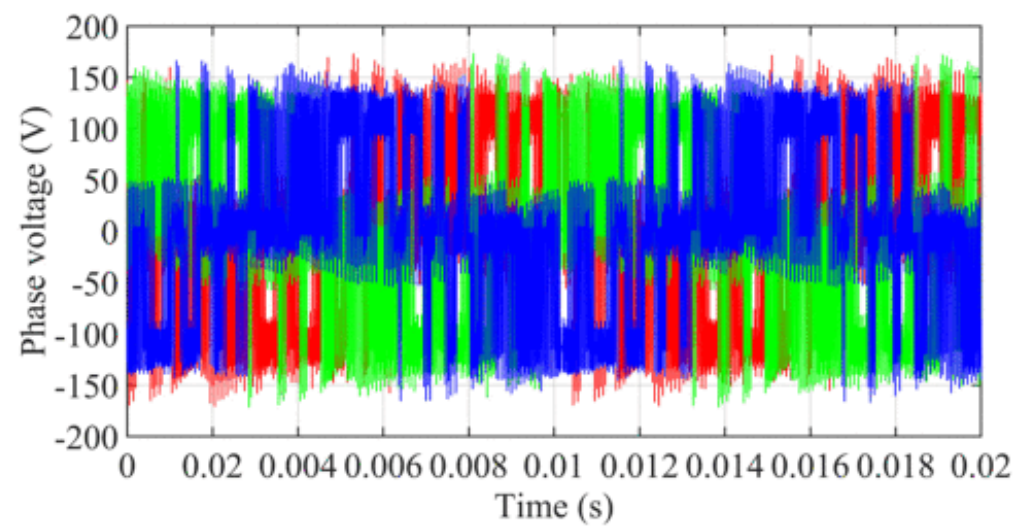

(a)

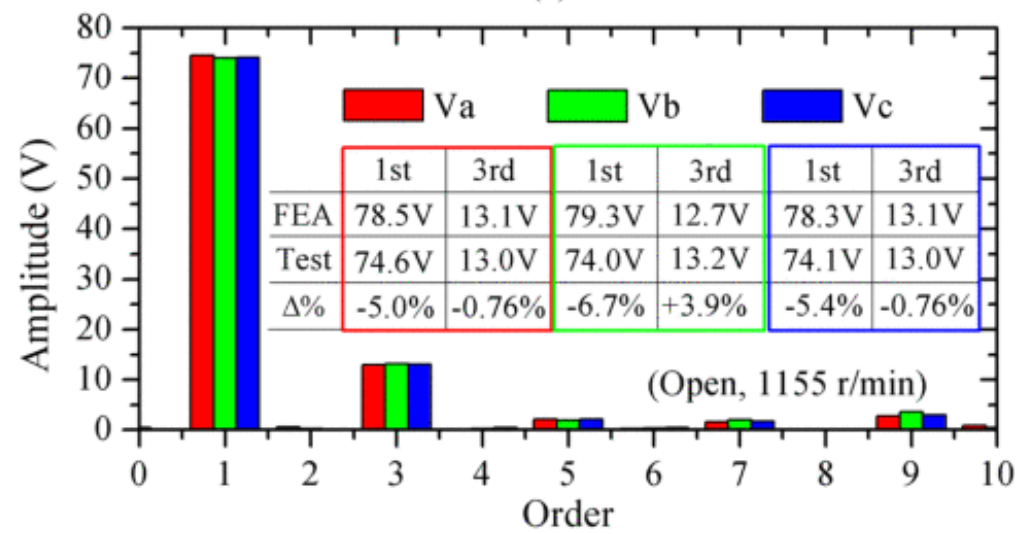

(b)

Fig. 13. Winding voltage waveforms at $1155 \mathrm{r} / \mathrm{min}$ with open-end winding. (a) PHASE voltage waveform (red: $V_{a}$; green: $V_{b}$; and blue: $V_{c}$ ). (b) FFT of (a).

Fig. 14 shows the 0 -axis, $d$-axis and $q$-axis voltages. The operating point at $1155 \mathrm{r} / \mathrm{min}, 5.1 \mathrm{~N} \cdot \mathrm{m}$ with open end windings is taken as an example. As can been seen in Figs. 14(a) and (b) that the 0 -axis voltage contains the third harmonics, of which the amplitude is $26.1 \mathrm{~V}$. The average values of $d$-axis and $q$-axis voltages are -68.6 and 28.3 $\mathrm{V}$, respectively. According to $(9)$, the predicted $d-, q-$, and 0 -axis voltage can be obtained by

$$
\left\{\begin{array}{c}
V_{d}=-L_{q} i_{q} \omega-R_{S} i_{d} \stackrel{R_{S}=0}{\approx}-61.5[\mathrm{~V}] \\
V_{q}=\left(L_{d} i_{d}+\Psi_{p m}\right) \omega-R_{S} i_{q} \stackrel{R_{S}=0}{\approx} 28.2[\mathrm{~V}] \\
V_{0}=3 \omega L_{\Delta} \sqrt{i_{d}^{2}+i_{q}^{2}}=15.8[\mathrm{~V}]
\end{array}\right.
$$

where $i_{d}=-2.91 \mathrm{~A} ; i_{q}=7.28 \mathrm{~A}$ (testing results); $\omega=2 \pi f=604.75 \mathrm{rad} / \mathrm{s}$; inductances are based on FE results (see Fig. 6): $L_{S 2}=2.22 \mathrm{mH}, L_{\Delta}=0.5 L_{S 2}=1.11 \mathrm{mH} ; L_{d}=11.52 \mathrm{mH}, L_{q}=14.0 \mathrm{mH}$. It shows that the measured $q$-axis voltage value matches well with theoretical results while there is a $\sim 10 \%$ difference between measured $d$-axis voltage and its FEA result. Therefore, the $L_{q}$ inductance is modified based the testing results: $L_{q}=15.6 \mathrm{mH}$. Accordingly, $L_{S 2}=3.71 \mathrm{mH}$ while $L_{\Delta}=0.5 L_{S 2}=1.85 \mathrm{mH}$. 


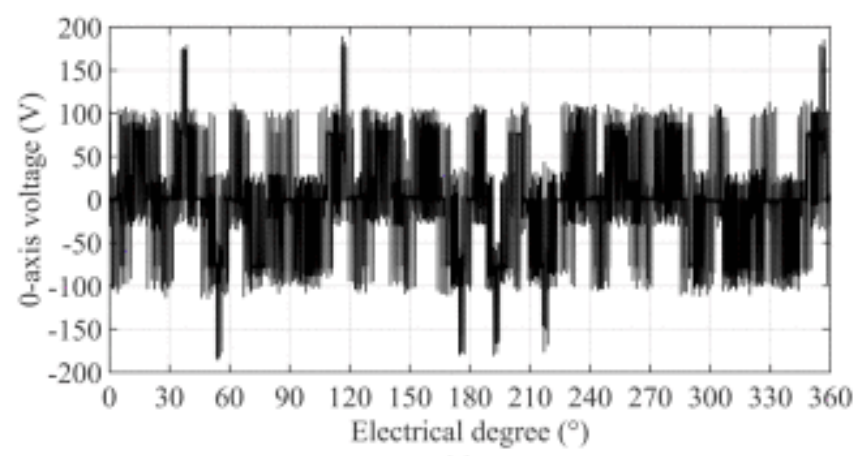

(a)

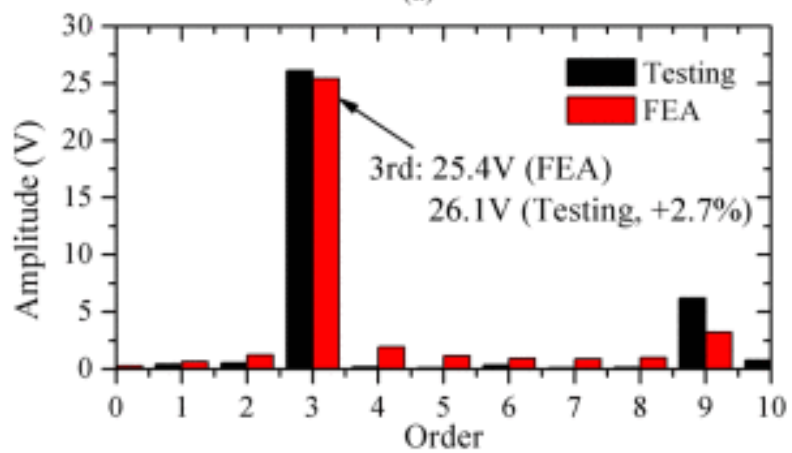

(b)

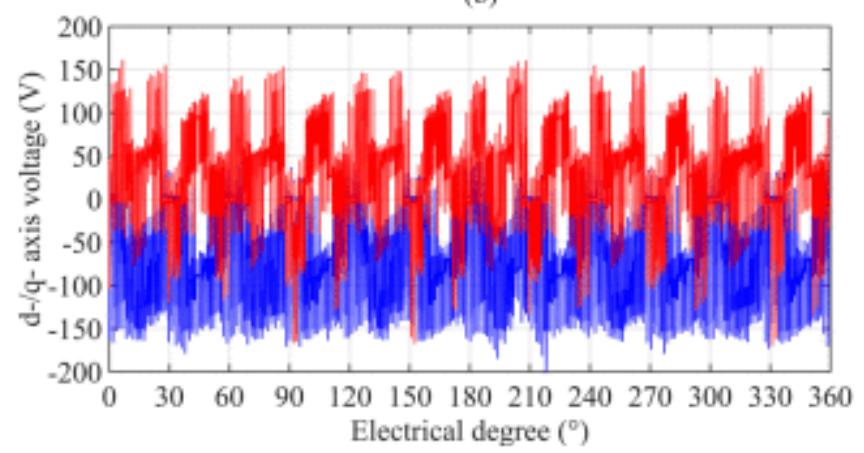

(c)

Fig. 14. 0 -axis, $d$-axis and $q$-axis voltage at $1155 \mathrm{r} / \mathrm{min}$ with open-end winding. (a) 0 -axis voltage. (b) FFT of (a). (c) Phase voltage waveform (blue: $V_{d}$; red: $V_{q}$ ).

Based on the updated machine parameters, the 0 -axis voltage is given as

$$
V_{0}=3 \omega L_{\Delta} \sqrt{i_{d}^{2}+i_{q}^{2}}=26.5[\mathrm{~V}]
$$

(13)

The modified 0 -axis voltage $(26.5 \mathrm{~V}$ ) aligns well with the testing result $(26.1 \mathrm{~V})$. The difference between predicted and measured results is due to third-harmonic back EMF, cross coupling and stator resistance, which are ignored in $\underline{12}$ ) for simplicity. This well proves that the third harmonic component is due to rotor saliency under the condition of fairly low winding mutual inductances.

While the showcased machine is a relatively small one, the following discussions are extended to cover the impact of this phenomenon for other machine design / operating conditions: 


\section{A. Impact on High-Speed Open-End-Winding Machine Drives}

In order to have sinusoidal winding current profile, third harmonics will be injected in phase voltages. The PWM switching frequency should be high enough to provide sufficient bandwidth for the extra time harmonics injected in phase windings. In this article, the electrical frequency of the third-harmonic component is $288.75 \mathrm{~Hz}$ at $1155 \mathrm{r} / \mathrm{min}$ while the switching frequency is $10 \mathrm{kHz}$ which is high enough to deal with the third harmonics. However, this could be a challenge for a high-speed machine design of which the electrical frequency is very high. With few switching times during each electric period, it is expected that more current harmonics and higher current ripple can be observed.

Since the saliency ratio of magnetically-isolated FSCW-IPM machine is low, the amplitude of the third-harmonic voltage is mainly determined by winding current amplitude as well as electrical frequency. That is to say, the third harmonics have a bigger impact in high-speed, high-current machine designs.

\section{B. Impact on Unbalanced Operation}

Open-end-winding machine drives are fault-tolerant when losing one of its three-phase windings by adjusting the amplitude and phase angle in the remaining two phases [22]. For postfault control, 0 -axis current $i_{0}$ is obviously non zero. The flux equation in $d-q-0$ reference frame is then given by

$$
\psi_{d q 0}=\left[\begin{array}{l}
\psi_{d} \\
\psi_{q} \\
\psi_{0}
\end{array}\right]=\left[\begin{array}{c}
L_{d} i_{d}-L_{\Delta} \sin 3 \theta i_{0}+\Psi_{p m} \\
L_{q} i_{q}+L_{\Delta} \cos 3 \theta i_{0} \\
-L_{\Delta} \sin 3 \theta i_{d}+L_{\Delta} \cos 3 \theta i_{q}+L_{0} i_{0}
\end{array}\right] .
$$

Assume that phase $\mathrm{C}$ winding is open-circuited, remediation currents in $d-q-0$ and $a-b-c$ reference frames yield to

$$
\left\{\begin{array}{c}
I_{d} \cos \theta-I_{q} \sin \theta+i_{0}=i_{a} \\
I_{d} \cos \left(\theta-120^{\circ}\right)-I_{q} \sin \left(\theta-120^{\circ}\right)+i_{0}=i_{b} \\
I_{d} \cos \left(\theta+120^{\circ}\right)-I_{q} \sin \left(\theta+120^{\circ}\right)+i_{0}=0 .
\end{array}\right.
$$

Then, remediation currents in phases $A$ and $B$ can be represented by id and iq currents

$$
\left\{\begin{array}{c}
i_{a}=\sqrt{3} I_{d} \sin \left(\theta+60^{\circ}\right)+\sqrt{3} I_{q} \cos \left(\theta+60^{\circ}\right) \\
i_{b}=\sqrt{3} I_{d} \sin \theta+\sqrt{3} I_{q} \cos \theta .
\end{array}\right.
$$

By applying Park's equation and neglecting stator winding resistance $\left(R_{S} \approx 0\right)$, voltage equation in $d-q-0$ reference frame is given by $(17)$. Eventually, $(18)$ is obtained by applying the inverse transformation $\left(C^{-1}\right)$ (see (17) and (18) shown at the top of the next page). As can be seen in (18), the third- and fifth-harmonic components are injected into phase voltages in postfault operation.

A detailed study has been conducted in ANSYS Maxwell 2D. Current excitations in the remaining two phases are shown in Fig. 15 while Fig. 16 shows the torque profile. By increasing the current by a factor of 1.732, the average torque of the machine is $0.97 \mathrm{p} . \mathrm{u}$. while the torque ripple is $0.54 \mathrm{p} . \mathrm{u}$. 


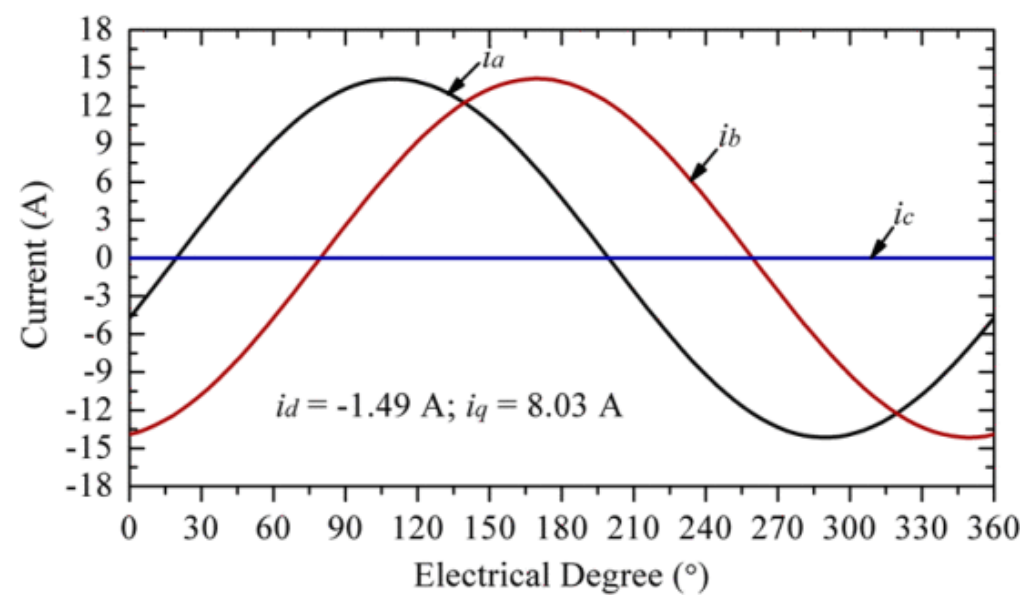

Fig. 15. Current excitations during post fault control.

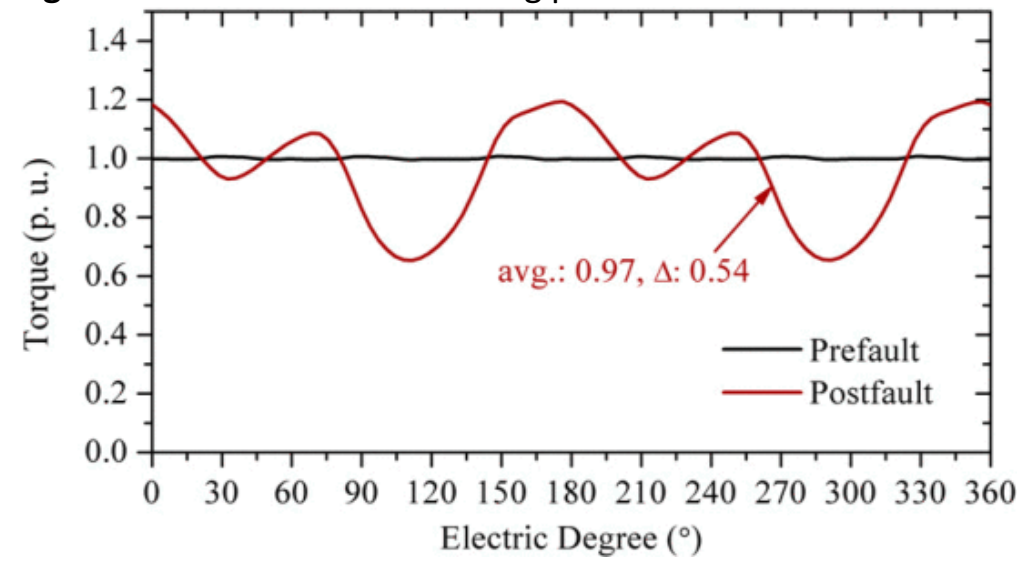

Fig. 16. Torque profile.

As can be seen in Fig. 17(a), due to lower saturation level, the self-inductance of the open-circuited phase $C$ $(12.13 \mathrm{mH})$ is higher than that of the other two phases $(\sim 11 \mathrm{mH})$. In addition, more harmonics can be observed for the postfault inductance, which results in severe distortion in the $d q 0$ inductance matrix [see Fig. 17(b)]. Phase voltage waveforms and spectrums are shown in Fig. 18(a) and (b), respectively. As can be seen in Fig. 18(b), the third- and fifth-harmonic components account for 0.19 p.u. and 0.14 p.u., respectively. The third harmonic is comparable to healthy operation while the value of the fifth harmonic is much higher than healthy operation ( 0.033 p.u. in Fig. 8). These harmonics should be considered when designing the bandwidth of the drives 


$$
\begin{aligned}
& {\left[\begin{array}{c}
v_{d} \\
v_{q} \\
v_{0}
\end{array}\right]=\left[\begin{array}{c}
\frac{\omega L_{\Delta} \sqrt{I_{d}^{2}+I_{q}^{2}}}{2}\left\{\left[\cos \left(2 \omega t-2 \pi / 3-\arctan \frac{I_{d}}{I_{q}}\right)\right]+3\left[\sin \left(4 \omega t+2 \pi / 3+\arctan \frac{I_{d}}{I_{q}}\right)\right]\right\}-\omega L_{q} I_{q} \\
\frac{\omega L_{\Delta} \sqrt{I_{d}^{2}+I_{q}^{2}}}{2}\left\{\left[\cos \left(2 \omega t-2 \pi / 3+\operatorname{arccot} \frac{I_{d}}{I_{q}}\right)\right]-3\left[\sin \left(4 \omega t+\frac{2 \pi}{3}-\operatorname{arccot} \frac{I_{d}}{I_{q}}\right)\right]\right\}+\omega_{r} L_{d} I_{d}+\omega_{r} \Psi_{p m} \\
\omega \sqrt{\left(I_{d}^{2}+I_{q}^{2}\right)}\left[-L_{0} \cos \left(\omega t+2 \pi / 3+\arctan \frac{I_{d}}{I_{q}}\right)+3 L_{\Delta} \cos \left(3 \omega t+\arctan \frac{I_{d}}{I_{q}}\right)\right]
\end{array}\right]} \\
& v_{a}=\frac{\omega L_{\Delta} \sqrt{I_{d}^{2}+I_{q}^{2}}}{2}\left\{-\cos \left(\omega t-2 \pi / 3-\arctan \frac{I_{d}}{I_{q}}\right)-3 \cos \left(5 \omega t+\frac{2 \pi}{3}+\arctan \frac{I_{d}}{I_{q}}\right)\right\}-\omega L_{q} I_{q} \sin (\omega t) \\
& +\left(\omega L_{d} I_{d}+\omega \Psi_{p m}\right) \cos (\omega t)+\omega \sqrt{\left(I_{d}^{2}+I_{q}^{2}\right)}\left[-L_{0} \cos \left(\omega t+2 \pi / 3+\arctan \frac{I_{d}}{I_{q}}\right)-3 L_{\Delta} \cos \left(3 \omega t+\arctan \frac{I_{d}}{I_{q}}\right)\right] \\
& v_{b}=\frac{\omega L_{\Delta} \sqrt{I_{d}^{2}+I_{q}^{2}}}{2}\left\{-\cos \left(\omega t-\arctan \frac{I_{d}}{I_{q}}\right)-3 \cos \left(5 \omega t+\arctan \frac{I_{d}}{I_{q}}\right)\right\}-\omega L_{q} I_{q} \sin (\omega t-2 \pi / 3)+\omega L_{d} I_{d} \cos (\omega t-2 \pi / 3) \\
& +\omega \Psi_{p m} \cos (\omega t-2 \pi / 3)+\omega \sqrt{\left(I_{d}^{2}+I_{q}^{2}\right)}\left[-L_{0} \cos \left(\omega t+2 \pi / 3+\arctan \frac{I_{d}}{I_{q}}\right)-3 L_{\Delta} \cos \left(3 \omega t+\arctan \frac{I_{d}}{I_{q}}\right)\right] \\
& v_{c}=\frac{\omega L_{\Delta} \sqrt{I_{d}^{2}+I_{q}^{2}}}{2}\left\{-\cos \left(\omega t+2 \pi / 3-\arctan \frac{I_{d}}{I_{q}}\right)-3 \cos \left(5 \omega t-2 \pi / 3+\arctan \frac{I_{d}}{I_{q}}\right)\right\}-\omega L_{q} I_{q} \sin (\omega t+2 \pi / 3) \\
& +\omega L_{d} I_{d} \cos (\omega t+2 \pi / 3)+\omega \Psi_{p m} \cos (\omega t+2 \pi / 3)+\omega \sqrt{\left(I_{d}^{2}+I_{q}^{2}\right)} \\
& \times\left[-L_{0} \cos \left(\omega t+2 \pi / 3+\arctan \frac{I_{d}}{I_{q}}\right)-3 L_{\Delta} \cos \left(3 \omega t+\arctan \frac{I_{d}}{I_{q}}\right)\right]
\end{aligned}
$$



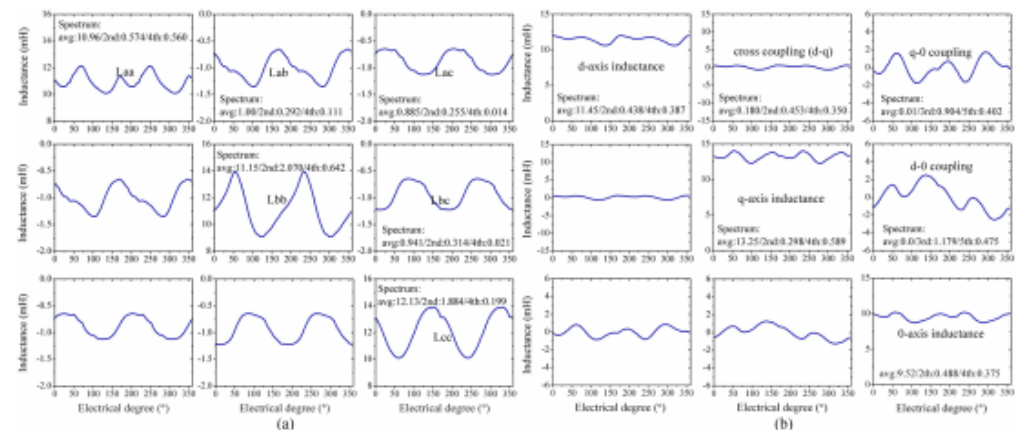

Fig. 17. Load inductance (excitation: sinusoidal current $14.15 \mathrm{~A}, \gamma=10.5^{\circ}$, and speed: $1155 \mathrm{r} / \mathrm{min}, T_{a v}=0.97$ per unit, $\Delta T / T_{a v}=56.1 \%$, saliency ratio: 1.157). (a) Inductance matrix in abc reference frame. (b) Inductance matrix in $d q 0$ reference frame.
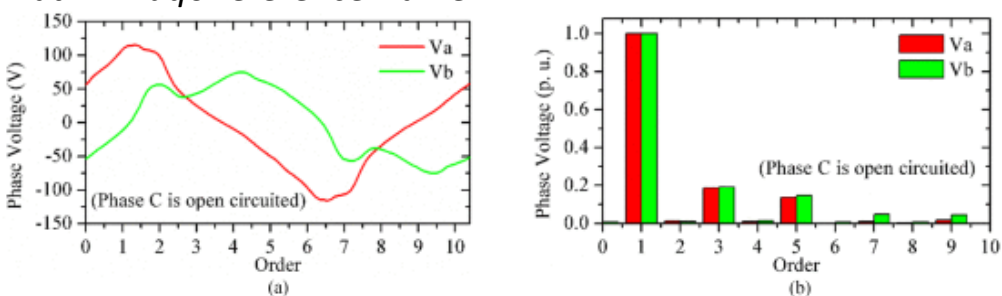

Fig. 18. Voltage waveform (Excitation: sinusoidal current $14.15 \mathrm{~A}, \gamma=10.5^{\circ}$, speed: $1155 \mathrm{r} / \mathrm{min}$ ). (a) Phase voltage profile. (b) Spectrum of (a).

\section{SECTION VI. Conclusion}

This article investigates the coupling between $d$-/q-axis and 0 -axis components in a magnetically-isolated threephase FSCW-IPM machine without neutral point constraint. Key insights are summarized as follows.

1. Coupling between $d-/ q$ - axis and zero-axis is due to negligible mutual inductance and rotor saliency, which can generally be observed in many of the FSCW-IPM machines when SPP $\neq 1 / 4$ or $1 / 2$.

2. Considering only the second-order harmonic component of winding self inductance, the third harmonic is introduced in the coupling terms of $d-/ q$-axis and 0 -axis, which finally results in the third-order phase voltage harmonics.

3. In case of a magnetically-isolated FSCW-IPM machines with Y-connected winding, the third harmonic can be cancelled out in terms of line-to-line voltage.

4. For fault-tolerant drives without the neutral point constraint, harmonics should be taken into account in the feedforward block of closed-loop control to improve the performance of the current regulator. The parameter of the proportional integral (PI) current regulator should be carefully tuned as well to allow sufficient bandwidth for the extra time harmonics injected in phase windings;

5. Harmonic components are determined by saliency ratio. Although the FSCW-IPM machine generally exhibits poor saliency (1.215 for the machine studied in this article), the IPM design is still of interest for metrics, such as PM protection against demagnetization, and high speed operation without requiring a retaining sleeve.

6. Mutual inductance has been neglected in theoretical derivations. However, the mutual inductance cannot be completely ignored in a real machine model. For the specific design investigated in this article, the mutual inductance is significant due to local saturation. 
7. Magnetic saturation and winding open-circuit result in more harmonics and parameter imbalance. The proposed analytical method can be extended to account for the complex harmonics in a real model.

\section{References}

1. B. C. Mecrow, A. G. Jack, J. A. Haylock and J. Coles, "Fault tolerant permanent magnet machine drives", IEE Proc. Elect. Power Appl., vol. 143, no. 6, pp. 437-442, Nov. 1996.

2. A. G. Jack, B. C. Mecrow and J. A. Haylock, "A comparative study of permanent magnet and switch reluctance motors for high-performance fault-tolerant applications", IEEE Trans. Ind. Appl., vol. 32, no. 4, pp. 889-895, Jul./Aug. 1996.

3. C. Tong, F. Wu, P. Zheng, B. Yu, Y. Sui and L. Cheng, "Investigation of magnetically-isolated multiphase modular permanent-magnet synchro- nous machinery series for wheel-driving electric vehicles", IEEE Trans. Magn., vol. 50, no. 11, Dec. 2014.

4. D. Ishak, Z. Q. Zhu and D. Howe, "Comparison of PM brushless motors having either all teeth or alternate teeth wound", IEEE Trans. Energy Convers., vol. 21, no. 1, pp. 95-103, Mar. 2006.

5. F. Wu, P. Zheng and T. M. Jahns, "Analytical modeling of interturn short circuit for multiphase faulttolerant PM machine with fractional-slot concentrated windings", IEEE Trans. Ind. Appl., vol. 53, no. 3, pp. 1994-2006, May/Jun. 2017.

6. B. Lee, Z. Q. Zhu and L. Huang, "Investigation of torque production and torque ripple reduction for sixstator/seven-rotor-pole variable flux reluctance machines", IEEE Trans. Ind. Appl., vol. 55, no. 3, pp. 2510-2518, May/Jun. 2019.

7. B. Nanda and P. Kumar, "Determination of $d$ and $q$ axes inductances for steady state model analysis of PM motor with non-ideal machine parameters", Proc. IEEE Trans. Elect. Conf. Expo., pp. 1-6, Jun. 2019.

8. J. Chen, J. Li, R. Qu and M. Ge, "Magnet-frozen-permeability FEA and DC-biased measurement for machine inductance: application on a variable-flux PM machine", IEEE Trans. Ind. Electron., vol. 65, no. 6, pp. 4599-4607, Jun. 2018.

9. P. C. Palavicino, D. Bobba, M. Liu and B. Salioglu, "Fast computation method to obtain typical machine waveforms applied to a 6/4 FSPM machine", Proc. IEEE Trans. Elect. Conf. Expo., pp. 809-814, Jun. 2018.

10. S. Mukundan, H. Dhulipati, J. Tjiong and N. C. Kar, "Parameter determination of PMSM using coupled electromagnetic and thermal model incorporating current harmonics", IEEE Trans. Magn., vol. 54, no. 11, pp. 1-5, Nov. 2018.

11. S. Li, S. Zhang, C. Gong, T. G. Habetler and R. G. Harley, "An enhanced analytical calculation of the phase inductance of switched reluctance machines", IEEE Trans. Ind. Appl., vol. 55, no. 2, pp. 1392-1407, Mar./Apr. 2019.

12. S. Wu, L. Guo, H. Wang, Y. Gao, T. Shi and C. Xia, "Inductance calculation of interior permanent magnet machines considering asymmetrical saturation of the bridge", IEEE. Trans. Magn., vol. 55, no. 11, Nov. 2019.

13. M. V. Terzic, H. Li, B. Bilgin and A. Emadi, "Comparison of experimental methods for electromagnetic characterization of switched reluctance motors", Proc. 13th Int. Conf. Elect. Mach., pp. 1881-1888, Sep. 2018.

14. P. B. Reddy, A. M. EL-Refaie, Kum-Kang Huh, J. K. Tangudu and T. M Jahns, "Comparison of interior and surface PM machines equipped with fractional-slot concentrated windings for hybrid traction applications", IEEE Trans. Energ. Convers., vol. 27, no. 3, pp. 593-602, Sep. 2012.

15. C. M. Spargo, B. C. Mecrow, J. D. Widmer and C. Morton, "Application of fractional-slot concentrated windings to synchronous reluctance motors", IEEE Trans. Ind. Appl., vol. 51, no. 2, pp. 1446-1455, Mar./Apr. 2015. 
16. J. K. Tangudu, T. M. Jahns and A. M. EL-Refaie, "Unsaturated and saturated saliency trends in fractionalslot concentrated-winding interior permanent magnet machines", Proc. IEEE Energy Convers. Congr. Expo., pp. 1082-1089, 2010.

17. G. Choi and T. M. Jahns, "PM synchronous machine drive response to asymmetrical short-circuit faults", Proc. IEEE Energy Convers. Congr. Expo., pp. 622-629, 2014.

18. F. Wu, P. Zheng, Y. Sui, B. Yu and P. Wang, "Design and experimental verification of a short-circuit proof six-phase permanent magnet machine for safety critical applications", IEEE Trans. Magn., vol. 50, no. 11, Nov. 2014.

19. D. W. Novotny and T. A. Lipo, Vector Control and Dynamics of AC Drives, London, U.K.:Oxford Univ. Press, 1996.

20. B. Welchko, T. Lipo, T. M. Jahns and S. Schulz, "Fault tolerant three- phase ac motor drive topologies: A comparison of features cost and limitations", IEEE Trans. Power Electron., vol. 19, no. 4, pp. 1108-1116, Jul. 2004.

21. A. Pouramin, R. Dutta and M. F. Rahman, "Design optimization of a spoke-type FSCW IPM machine to achieve low torque ripple and high torque density under a wide constant power speed range", Proc. IEEE Energy Convers. Congr. Expo., pp. 6914-6921, Sep. 2018.

22. F. Wu, H. Ge and A. M. EL-Refaie, "Partially-coupled d-q-0 components of magnetically-isolated FSCW IPM machines in pre-and post-fault control", Proc. IEEE Energy Convers. Congr. Expo., pp. 269-276, Sep. 2018. 